Kamchatk a Revista de análisis cultural N. 12

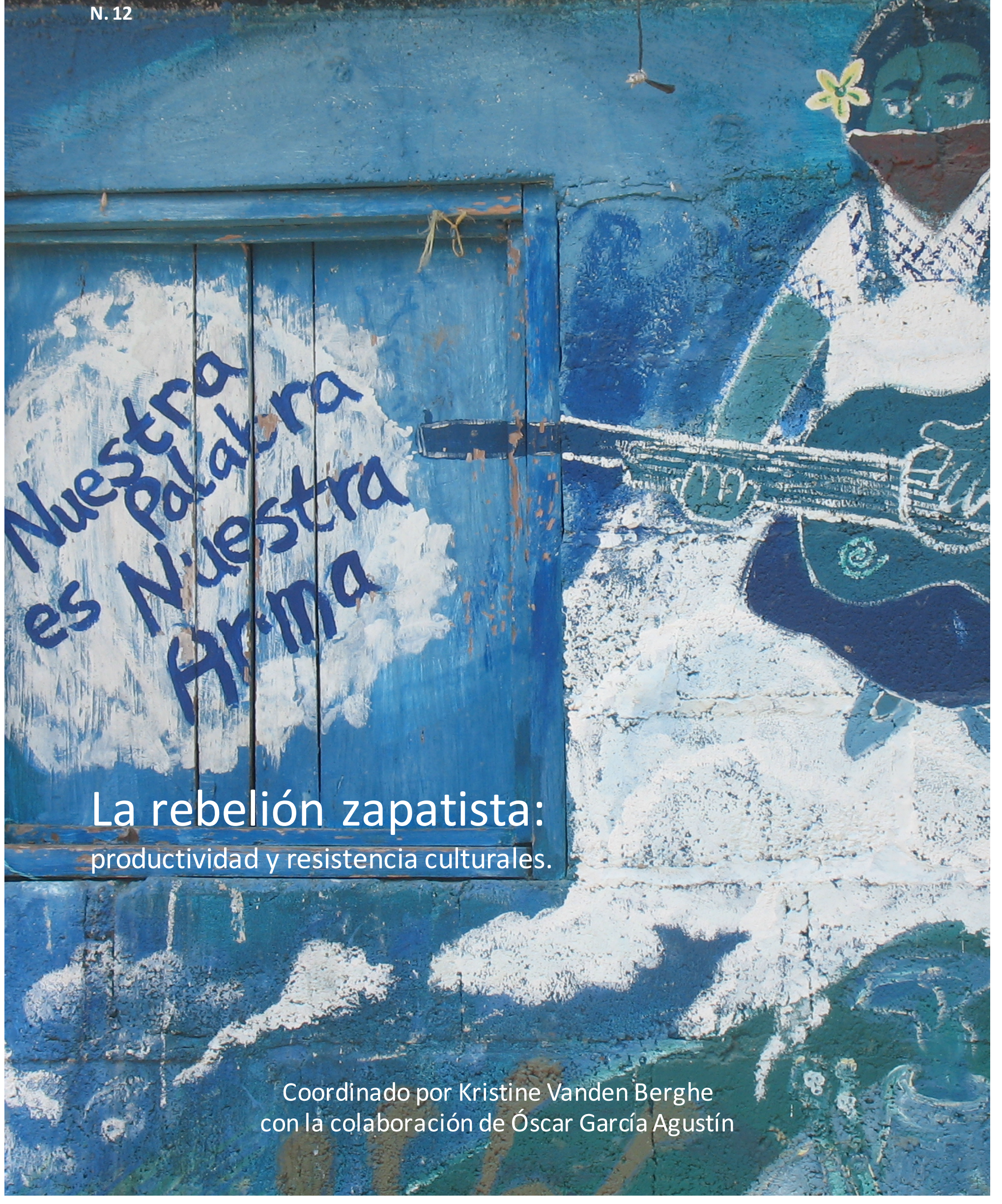




\title{
LA REBELIÓN ZAPATISTA: PRODUCTIVIDAD Y RESISTENCIA CULTURALES
}

KAMCHATKA. REVISTA DE ANÁLISIS CULTURAL 12 (2018)

\author{
Monográfico coordinado por KRISTINE VANDEN BERGHE \\ con la colaboración de ÓSCAR GARCíA AguSTíN \\ Fotografía de portada: Kristine Vanden Berghe
}

KRISTINE VANDEN BERGHE. La rebelión zapatista: productividad y resistencia culturales.

\section{Historia Y POLÍTICA}

FEDERICO BelLido PERIS. La identidad Neozapatista como proceso comunicativo.

JAIme ORTEgA ReynA. La importancia del comienzo: Louis Althusser, la crítica de la ideología y el zapatismo.

Nicolina Montesano Montessori. El movimiento Zapatista: una cultura politica híbrida y paradójica.

Elena Ansotegui. El discurso zapatista después de Marcos: de la ficción a la realidad o al revés.

MANUEl LARio BASTIDA. Reflejos globales del zapatismo. De Estados Unidos a Rusia pasando por Bélgica o Kurdistán.

\section{ARTES Y CULTURAS:}

Carlos Antonio Aguirre Rojas. Artes, ciencias y saberes neozapatistas. Nacer desde abajo el nuevo mundo no capitalista.

ELISSA RASHKIN. Mujeres zapatistas y producción videográfica en Chiapas.

MARTIN BAXMEYER. El mito universal. Reconstrucción y deconstrucción de la identidad indígena en Relatos de El Viejo Antonio del Subcomandante Marcos.

MÉlanie LÉtocart Araujo. Autoficción, historia y mito en la narrativa del Subcomandante Marcos.

Kristine VANDEN Berghe. The caracol and the beetle. A tension between ideology and form in the EZLN's literary production. 


\title{
EL DISCURSO ZAPATISTA DESPUÉS DE MARCOS:
}

\author{
DE LA FICCIÓN A LA REALIDAD O AL REVÉS
}

The zapatista discourse after Marcos: from fiction to reality or vice-versa

\author{
ELENA ANSOTEGUI \\ UNIVERSIDAD DE COPENHAGUE (DINAMARCA) \\ ansotegui@gmail.com https://orcid.org/0000-0002-4941-6504
}

\section{RECIBIDO: 30 DE AGOSTO DE 2018 ACEPTAdo: 14 DE NOVIEMBRE DE 2018}

RESUMEN: Este artículo quiere analizar uno de los últimos comunicados que el Subcomandante Insurgente Galeano, antes Marcos, ha hecho público a fines de diciembre del 2017 durante la celebración del II encuentro "ConCiencias por la Humanidad" titulado "Trump, la navaja de Ockham, el gato de Schrodinger y el gato-perro". La intención del análisis es constatar que el movimiento zapatista ha ido transformado su estrategia política en los últimos tres años, precisamente desde que el otrora Marcos realizase un relevo simbólico de su puesto como portavoz. La hipótesis de este artículo es que desde que Marcos es Galeano el zapatismo ha intentado constituir una nueva identidad basada en la necesidad de globalizar una lucha antisistema que afecta a un nuevo actor social: la humanidad en su conjunto. A través del uso de conceptos como "exotopía", "significante vacío" o "tercer espacio", basados en el trabajo de Bajtín, Laclau y Bhabha respectivamente se propone que este nuevo actor social está representado por la mujer, Marichuy, desde el campo de lucha político y el personaje de ficción Defensa Zapatista, desde el ético/estético.

PALABRAS CLAVE: Zapatismo, Subcomandante Galeano, significante vacío, tercer espacio, Marichuy

ABSTRACT: This article analyzes one of the most recent communiques made public at the end of December 2017 during the celebration of the $2^{\text {nd }}$ meeting "Con Ciencias por la Humanidad" by Subcomandante Insurgente Galeano, previously known as Marcos: Trump, Ockham's Razor, Schrodinger's Cat, and the Cat-Dog. The aim is to verify that the Zapatista movement has transformed its political strategy in the past three years since the former Marcos made a symbolic relay of his position as spokesman. The hypothesis is that since Marcos became Galeano, Zapatismo has attempted to constitute a new identity based on the need to globalize an anti-system struggle, which communicates to a new social actor: the humanity as a whole. Through the use of concepts as "exotopia", "empty signifier" and "third space" based on the works of Bakhtin, Laclau and Bhabha, respectively, the article proposes that the new social actor is represented by the woman, Marichuy as the political struggle, and by the fictional character, Defensa Zapatista, as the ethical and aesthetical struggle.

KEYWORDS: Zapatismo, Subcomandante Galeano, empty signifier, third space, Marichuy.

Ansotegui, Elena.

"El discurso zapatista después de Marcos: de la ficción a la realidad o al revés". Kamchatkea. Revista de análisis cultural 12 (Diciembre 2018): 79-98. DOI: 10.7203/KAM.12.12995 ISSN: 2340-1869

Monográfico LA REBELIÓN ZAPATISTA: PRODUCCIÓN Y RESISTENCIAS CULTURALES 


\section{INTRODUCCIÓN}

El 27 de diciembre de 2017 el Subcomandante Insurgente Galeano, nuevo pseudónimo desde mayo de 2014 del Subcomandante Insurgente Marcos, vocero del Ejército Zapatista de Liberación Nacional (EZLN) realiza una ponencia de unos 37 minutos durante la segunda edición del encuentro "ConCiencias por la Humanidad: las Ciencias frente al muro". Esta ponencia, que puede ser escuchada en internet (SupGaleano 2017d) se publica al día siguiente en Enlace Zapatista, en Twitter y en Facebook bajo el título "Trump, la navaja de Ockham, el gato de Schrödinger y el gato-perro" (SupGaleano, 2017c).

El comunicado es el segundo de tres ponencias que el Subcomandante Insurgente Galeano (a partir de ahora SIG) realiza durante los cinco días que dura el encuentro en CIDECIUniTierra, en la localidad mexicana de San Cristóbal de Las Casas (Chiapas). Está compuesto por un texto firmado y seguido por un relato titulado "Del cuaderno de apuntes del gato-perro: El misterioso caso de las mantecadas desaparecidas". Este comunicado podría interpretarse como algo a caballo entre una broma intelectual y un aviso de muerte, y ha de ser entendido como una parte dentro del conjunto de las tres ponencias del encuentro que giran alrededor de un mismo eje: el crimen. El estilo irónico e intertextual coincide con el de otros textos del finado Subcomandante Marcos, sin embargo, deja traslucir una preocupación especial por la humanidad en su conjunto como actor-víctima del sistema capitalista, representado por la mujer en general. La mujer como símbolo del crimen neoliberal se concretiza en algunas partes del comunicado en la aspirante a candidata a las elecciones del 2018, Marichuy, o se transforma en metáfora a través de la invención del personaje de Defensa Zapatista, que vive una cuádruple condición de vulnerabilidad: mujer, indígena, niña y rebelde.

La intención de este artículo, que responde a un proyecto de investigación más amplio sobre la narrativa utópica en los movimientos sociales de América Latina, es la de analizar este comunicado del SIG sin limitarse a los aspectos puramente lingüísticos o a los sociales sino intentando sonsacar aspectos multidisciplinares a través de la combinación de elementos como la intertextualidad, la exotopía y la creación de un Tercer Espacio, necesario como lugar de resistencia.

El objetivo es demostrar cómo los cambios literarios basados en la apropiación de palabras y en la creación de metáforas y metonimias a las que se les dan un nuevo sentido alternativo, están enfocados a explicar el cambio de estrategia política actual dentro del seno del Congreso Nacional Indígena. Es decir, el objetivo de este trabajo es demostrar que la praxis actual del zapatismo requiere la creación de un lenguaje que se adapte al mismo.

El análisis obliga a que otras fuentes secundarias sean tomadas en cuenta ya que este texto que aquí se analiza está en estrecha relación con otros, principalmente con las dos otras ponencias que el SIG realiza durante este encuentro, lo que ayuda a crear un universo de protesta que, a través de la mezcla de tiempos, espacios y expresiones literarias, se transforma en una estrategia comunicativa capaz de generar movilización social y política. 
El marco de análisis de este texto va a estar formado por las siguientes nociones: intertextualidad entendida a partir del concepto de dialogismo en Mijaíl Bajtín, que se opone al de monologismo, ese discurso de una sola voz que ignora la polifonía de lo que no se halla en el centro hegemónico. La relación entre el texto a analizar y otros textos es aquí un desafío epistemológico ya que crea un discurso de espejos reflejados e infinitos cuya intención por parte del emisor es mostrar se en oposición ante el discurso hegemónico único y cerrado.

Bajtín ha sido interpretando, ordenado y dado a conocer a través de sus discípulos, pero en este trabajo deseo acercarme directamente no tanto a la herencia sino a la idea que este filosofo ruso desvela sobre la relación entre la pluralidad de agentes del discurso que más que una teoría lingüística es entendida en este artículo como una teoría ética, cuyo pilar principal es que "la realidad del ser humano está en el ser del otro" (Zavala, 1997: 184).

Para Bajtín, el texto, a diferencia de la distinción hegeliana basada en una relación binaria, antitética y cerrada, es siempre inconcluso (Ibídem, p. 185) ya que al ser recibido por el otro se abre a múltiples interpretaciones dinámicas y cambiables, contradictorias e influenciadas por los cambios históricos; lo que Iris Zavala llama "el pensamiento participativo" (idem). En sus escritos sobre la filosofía del acto desarrollados en la convulsa época de la revolución rusa y la I Guerra Mundial, Bajtín explica cómo el lenguaje es a la vez ética y estética: ética porque sale al encuentro del otro y estética porque lo hace a través de símbolos (Bajtin, 1997). Este concepto es desarrollado más adelante por uno de los discípulos de Bajtín, Tzvetan Todorov, en relación a los textos que, a través de un intercambio dialógico, salen al encuentro de las otras voces (Zbinden, 2006).

En el texto a analizar se localizan además ejemplos de heterofonía, heterología y heteroglosia vinculados al concepto de exotopía. La exotopía es un neologismo de raíz griega inventado por Todorov para traducir al francés el también neologismo ruso inventado por Bajtín "vnenakhodimost" que podría explicarse como "el hecho de encontrarse fuera". Este término implica que comprender no es sólo ponerse en el lugar del otro ni traducir una lengua extranjera a la de uno mismo. Comprender es la transformación de "uno-mismo" en "otro-mismo". Bajtín resume la relación con el otro en una formula ontológica que recuerda al cogito ergo sum cartesiano, pero dando prioridad al diálogo frente a la razón: "ser es comunicarse" (Silvestri, 1993).

Emplearé la exotopía para llevar a cabo la lectura de este comunicado zapatista ya que me parece interesante que este término sea explicado por Todorov precisamente en su libro La conquista de América, el problema del otro a través de la relación fracasada en términos éticos y comunicativos entre la cosmovisión de los nativos en América latina y la de los conquistadores españoles (Todorov 1987). En este artículo se emplea el término exotopía como una moneda de dos caras, una ética y otra estética. Por una parte, la exotopía es la condición necesaria para el conocimiento profundo del otro. Por otra, las prácticas comunicativas humanas, es decir, el salir al encuentro del otro, siempre involucran una multiplicidad de lenguajes. Esta multiplicidad es explicada por Bajtín a través de la historia del campesino analfabeto:

he prayed to God in one language (Church Slavonic), sang songs in another, spoke to the 
family in a third, and, when starting to dictate a petition for the district authority to someone who could write, tried to speak in a fourth (the official-written language of documents) (Bakhtin, 1981).

También emplearé el concepto “Tercer Espacio" de Homi Bhabha, desarrollado por Óscar García Agustín (2009) como un espacio que desplaza la lógica binaria (negro/blanco, yo/otro) y que sirve de cuestionamiento del discurso hegemónico (Bhabha, 2002: 20) a la vez que propone la polifonía de un lenguaje colectivo, híbrido, contradictorio y transgresor. En este sentido se puede decir que tanto Bhabha como Bajtín superan, denunciándola, la concepción binaria del lenguaje. El Tercer Espacio es, por tanto, entendido no sólo como un lugar geográfico sino como un lugar cultural condicionado por una presión entre identidades hegemónicas y periféricas en el que necesariamente se crea un caldo de cultivo para la transformación social y para el surgimiento de nuevos actores sociales que no están ni en el centro ni en la periferia (García Agustín 2009). En este sentido la intertextualidad y la exotopía son entendidas en este artículo como parte constituyente del Tercer Espacio ya que alimentan un discurso heterogéneo enfrentado al discurso dominante.

La metodología empleada combinará estas herramientas discursivas con otras sociales provenientes de Ernesto Laclau, el cual considera lo social como un complejo antagónico. Según este teórico no puede existir un discurso que cierre todas las posiciones; por lo tanto, siempre hay una lucha inherente y el discurso es una plataforma para llevar a cabo la lucha ideológica. Además, cada sociedad desarrolla una serie de significantes vacíos que poseen un significado concreto para ella. La lucha ideológica consiste en crear un discurso cuyos significantes giren en torno a una misma identidad que además es contraria a la del contrincante, por ejemplo, "pueblo" enfrentado a "casta". La idea del discurso binario de Laclau queda, a mi entender, superada con la noción del Tercer Espacio, pero me interesa de este su concepto de "significante vacío" que, al estar vacío, invita a que se le llene con infinitos significados. El discurso zapatista no sólo llena significantes vacíos, sino que además vacía significantes de su significado hegemónico e inventa significantes para significados que carecían de significante en el discurso hegemónico.

Todo movimiento social, como movimiento que es, está en continua transformación, en inacabable construcción. Como indica Alberto Melucci un movimiento social se define por la acción de sus actores sociales que nunca es lineal sino llena de interacción y contradicción (1999). El EZLN ha sufrido desde 1994 hasta 2018 constantes modificaciones en sus tres dimensiones identitarias: la integración comunitaria de sus actores, la estrategia política y su compromiso utópico como proyecto alternativo de transformación social (Dubet, 1989). Trenzar estas tres dimensiones sin sufrir tensiones que destruyan la coherencia del movimiento es una tarea difícil que el EZLN ha sabido llevar a cabo con más o menos acierto. Lo que en este artículo se pretende es a través del análisis de uno de los últimos textos escritos por el otrora Subcomandante Marcos, comprobar la vigencia de este triple aparato de identidad colectiva: 1) quiénes son y cómo se integran los actores protagonistas en el EZLN hoy; 2) cuál es la estrategia política seguida actualmente y 3) cómo es su compromiso de transformación.

La hipótesis de este artículo es que el EZLN ha radicalizado su denuncia del régimen capitalista opresor a través de la adquisición de un pilar identitario que ha estado siempre presente pero que hoy se ha transformado en un nuevo ideario que hace que este movimiento traspase las 
fronteras de una zona sur de un país periférico y hable a toda la humanidad. Este pilar es la mujer, representada a la vez por una real Marichuy y por otra de ficción, la niña Defensa Zapatista.

\section{ACERCAMIENTO AL TEXTO ZAPATISTA: DEL DISCURSO A LA PRAXIS}

En este apartado se pretende presentar someramente algunos de los rasgos más llamativos de la evolución del discurso zapatista que siempre ha estado vinculada a los cambios de estrategia del movimiento.

El dualismo que surge a partir del momento en el que el neoliberalismo se convierte en el sistema-mundo de manera económica, pero sobre todo haciendo de su lógica un pensamiento único, se vive como un gran desafío en los países periféricos. Tal como señala Ana Esther Ceceña, México sea probablemente el país más expuesto a este neoliberalismo despiadado y de saqueo constante desde su nacimiento (2001). En México la creación de la nación tras la Independencia como espacio de identidad está vinculada a la lucha (Le Bot, 1997: 349-350) y los neozapatistas retoman esa tradición pero transforman la revolución en el fin y no en el medio a través del cual se toma el poder.

El discurso zapatista como discurso político ha de ser explicado atendiendo primeramente a la concepción de lo político entre los zapatistas. Términos como poder o democracia son vaciados de su significado hegemónico con el fin de rechazar tal significado. A la vez se llenan de un nuevo significado ético basado en el respeto a la participación de la sociedad civil, el rechazo a la toma del poder tal y como se practica en el Estado mexicano y sobre todo en la construcción de un espacio social donde la práctica de su ideal colectivo y ancestral pueda desarrollarse.

Los primeros años tras el levantamiento se habla de un "efecto Chiapas" definido por Antonio García de León como un estado de ánimo libertario, una paradoja que, surgida de la violencia, denuncia la violencia del aparato ilegítimo del gobierno mexicano (2001: 18 y ss. ).

Sin embargo, a pesar de no respetar las normas del juego político, desde su compromiso de deponer las armas, once días después del levantamiento armado el 1 de enero de 1994 y hasta el año 2001, este movimiento se caracterizó por una incesante búsqueda de espacios de interlocución con la sociedad civil mexicana e internacional (García Agustín 2009). En este período el EZLN consigue firmar un pacto histórico con el gobierno de Ernesto Zedillo, los Acuerdos de San Andrés (1996) lo que demuestra que el EZLN reconoce al Estado mexicano cierta autoridad (Ansotegui, 2018). Sin embargo, el cumplimiento de lo acordado nunca llega y la esperanza de que esto cambiase con la llegada de Vicente Fox al poder, proveniente del partido de la oposición, fracasa rotundamente durante la Marcha del Color de la Tierra, una movilización sin precedentes en la historia de México, donde, convocados por el Congreso Nacional Indígena y el EZLN, más de 200 mil manifestantes llegaron a la plaza del Zócalo para apoyar la causa indígena.

En esta primera etapa los comunicados zapatistas poseen un tono original, nunca antes visto en relación a una guerrilla o a un grupo de resistencia. El intelectual francés Regis Debray elogió el discurso zapatista al que consideraba no sólo romántico, como otros críticos, sino real e 
incluyente, "una verdadera revolución dentro de la revolución" (IPS, 1996). Por otra parte, el crítico mexicano Gabriel Zaid calificó el discurso zapatista de "ensalada posmoderna”, plagada de pastiches, parodia y metadiscurso (2011). El propio Marcos aseguró en su momento que lo que intentaba en los comunicados era:

resemantizar o darle un nuevo significante, y un nuevo significado a la palabra en la política, y sobre todo a la historia en la política. Y para eso recurrir a lo viejo, a la tradición histórica de los indígenas, a su tradición cultural para encontrar viejos personajes, viejas ideas, y en confrontación con las nuevas, ir construyendo este nuevo lenguaje zapatista. Estoy hablando de un lenguaje posmoderno que, paradójicamente, se nutre de la premodernidad histórica para poder constituirse en tanto que tal (Le Bot, 1997).

El fracaso del diálogo con el poder estatal mexicano inauguró una nueva etapa en la andadura zapatista. A partir del 2001 y hasta el 2006 los indígenas de Chiapas se concentraron en la creación de espacios de autonomía y de resistencia, esto es, en la plasmación práctica de su anhelo por un mundo mejor inaugurando los Caracoles y las Juntas de Buen Gobierno donde pudieran convivir numerosos pueblos heterogéneos entre sí (Zermeño, 2005: 237). Tras cinco años inventando una nueva forma de organización social y política, los zapatistas habían perdido adeptos y capacidad de movilización popular. Algunos comunicados de Marcos ponen de manifiesto su descontento general con periodistas e intelectuales nacionales e internacionales que no tienen la paciencia necesaria para entenderlos y que están, remedando al propio Marcos, en otro "calendario" y en otra "geografía" (S.I.M., 2003). En este contexto de aislamiento geográfico y de intento de diálogo con la sociedad civil surge la Otra Campaña como una contra-campaña durante las elecciones federales del 2006 donde los zapatistas intentan hacerse un hueco en el panorama del debate político mexicano. En contra de lo previsto esta Otra campaña termina violentamente con la represión estatal y la violación de al menos once mujeres en Atenco, hecho que despertó una solidaridad internacional con la causa zapatista (S.I.M., 2006; Mundo, 2016).

En diciembre del 2007 la celebración del Coloquio Internacional In Memoriam Andrés Aubry, "Planeta tierra: movimientos antisistémicos" sirvió para inaugurar una nueva vía comunicativa entre los zapatistas y el mundo intelectual. Con sus siete ponencias bajo el título "Ni el centro ni la periferia" el EZLN asienta las bases de un discurso antisistema e inicia la andadura en una nueva coordenada espacio-temporal, en un nuevo "calendario" y "geografía" donde la mujer se convierte en la representante de la lucha antisistema por antonomasia. (S.I.M., 2007ª; S.I.M., 2007b).

Y así pasa casi una década donde poco se escucha del movimiento zapatista hasta que en mayo de 2014 Marcos realiza un relevo generacional necesario en el liderazgo del EZLN, pero también un relevo de clase, de raza y de pensamiento (S.I.M., 2014). Su figura desaparece y el portavoz zapatista pasa a tener el nombre de Galeano, en homenaje a un compañero asesinado.

El reciente intento del EZLN, agrupado con otros grupos indígenas bajo el Congreso Nacional Indígena, de presentarse a las elecciones presidenciales de 2018 nos demuestra que este movimiento social aún es capaz de reinventarse a sí mismo y de inspirar a otros grupos sociales que buscan transformar el mundo desde la izquierda y desde abajo. Veinticinco años después del "efecto Chiapas" que revolucionó la izquierda mexicana, pretenden crear un nuevo efecto, el 
“efecto Marichuy”, con el que conseguir mantener viva la insurrección del 94. Como señalé en mi artículo "Todos somos Marichuy: poder y utopía en los zapatistas hoy", México está sufriendo una triple crisis estructural: política, social y moral. Ante esta crisis el EZLN se ha visto en la urgencia de reconstruir su identidad política (Ansotegui, 2018) para hacerla capaz de enfrentarse a una política totalitaria de mercado, de corrupción e impunidad que en los últimos veinticinco años no ha hecho sino generar una creciente "violentización" social.

En ese sentido la candidatura de Marichuy a las elecciones del 2018 aportó a la campaña electoral la voz de un México antisistema, pero sobre todo de un México hastiado de la violencia cotidiana. Marichuy representa la esperanza de una nueva concepción política que rechaza, como lo hiciera hace más de dos décadas, el tratado de libre mercado, pero que hoy, sobre todo, rechaza la violencia que éste sistema económico genera y que tiene a la mujer como su principal víctima.

Dejando a un lado los quinientos años de despojo y marginación que, como indica Magdalena Gómez se han convertido en "lugar común” de una retórica gastada por la izquierda, la propuesta del CNI quiere dejar constancia del impacto ecológico negativo del modelo neoliberal en el planeta tierra y de como este impacto afecta a la humanidad en su conjunto (Gómez, 2017). El SIG en su ponencia habla repetidamente del crimen que se está perpetrando delante de todos, en el que víctima y verdugo son la misma cosa. La denuncia indígena se convierte en denuncia de todos: todos somos Marcos, todos somos Marichuy, todos somos víctimas del sistema capitalista.

\section{GÉNERO ZAPATISTA, NI UNA COSA NI LA OTRA}

Desde una perspectiva literaria es difícil concluir a qué género pertenece el discurso zapatista. Quizás porque el discurso zapatista no es literatura. Descifrar en que caja habría que colocar a los textos zapatistas es un reto al que no voy a enfrentarme en estas páginas ya que considero que se está tratando con un discurso "muy otro" que además de imágenes estéticas posee un componente ético que le acerca a la filosofía política y un componente de resistencia que le vincula con el discurso político. El texto que aquí se quiere analizar ofrece diferentes estilos híbridos que han de ser vistos como una propuesta epistemológica típica de los escritos zapatistas integradora de numerosas prácticas discursivas donde el paratexto se sitúa al mismo nivel, incluso en ocasiones se fusiona con el texto, fracturando la distinción clásica entre las partes de un texto y dificultando el análisis tradicional del mismo. He aquí el reto académico que obliga a generar una nueva terminología o que, simplemente, desmonta la necesidad de generar una terminología.

El SIG sabe que, a pesar de que el texto es originariamente oral, éste se convertirá en comunicado escrito y podrá ser leído en diferentes geografías y tiempos; de ahí el saludo: "De nuevo buenos días, tardes, noches, madrugadas" (SupGaleano, 2017c). Por eso, este comunicado no es una charla con ciertas improvisaciones sino más bien un texto leído en voz alta perfectamente terminado y cuyo autor sabe que será divulgado a lectores del mundo entero. Este texto fue traducido simultáneamente al inglés (SupGaleano, 2017e) y posteriormente al italiano, portugués y alemán (SupGaleano 2017c). La conexión de este texto con otros anteriores se percibe desde las primeras líneas, en las que se hace alusión de manera paradójica al "difunto Marcos". Más adelante el SIG diferirá de su anterior avatar, Marcos, cuando señala que "a 
diferencia del difunto, a mi entender el capitalismo puede ser estudiado como un crimen" (Ibídem). Esto indica y demuestra, como sostiene la hipótesis de este trabajo, que ha habido cambios estructurales y estratégicos en las filas zapatistas, pero también cambios de pensamiento de tendencia radical, donde el neoliberalismo ha pasado de sistema que ataca a las minorías a sistema criminal que ataca a toda la humanidad.

En este análisis discursivo es importante recalcar la invención de neologismos cuya intención es la de crear una brecha entre el orden establecido y la desordenada realidad. El hecho de que el SIG aluda a "alguna, alguno, algunoa" (ibíd.) implica doblemente que desea romper con el orden patriarcal del lenguaje que en su forma masculina excluye a la femenina y que el zapatismo posee otra gramática en la que la creación de neologismos como algunoa es utilizado como recordatorio de que el mundo no es necesariamente binario, dividido entre hombre-mujer, reivindicando la inclusión de otras identidades. Los fenómenos de exotopía son una constante latente en el texto. El uso que acabamos de ver del neologismo algunoa le sirve al SIG para afirmar la existencia de un ser diferente que el lenguaje común ignora, para denunciar esta ignorancia y para reconocerlo como sujeto. De esta manera el lenguaje no sólo tiene un objetivo comunicativo sino también ético, el de acercarse a la negación del otro para afirmarla con una palabra nueva.

El diálogo entre los elementos discursivos, poéticos e ideológicos, esto es, la heteroglosia del lenguaje zapatista es usado como herramienta para construir el otro mundo posible pregonado desde hace 25 años. Esta heteroglosia es fundamental para concebir el Tercer Espacio del que se tratará más adelante ya que en ella se encuentra la apertura necesaria a otras voces y otras cosmovisiones.

Interpreto este comunicado como una voluntad por parte del SIG de transformar la concepción del ser indígena. Esta voluntad ha estado latente desde el origen del movimiento zapatista, caracterizado precisamente por devolver al indígena la dignidad necesaria para dejar de ser una identidad medida por la desigualdad para convertirse en una identidad medida por la resistencia y la denuncia. A este respecto Todorov (1987: 54 y ss.) desde un intento por entender cómo el europeo inventa al indio, concluye que tanto la visión del indígena como "buen salvaje" como la del "pobre perro" se deben a una incapacidad por parte del conquistador de percibir otra epistemología diferente a la suya. Los zapatistas, al abandonar las armas once días después del levantamiento de enero comenzaron su andadura hacia el Tercer Espacio, aquel que se escapa de la visión judío-cristiana de la ley de talión donde para vencer el mal que el enemigo provoca hay que emplear armas idénticas y hacerle el mismo mal. Siguiendo con Todorov, "la estrategia que pretende controlar la violencia del enemigo mediante una violencia comparable está condenada al fracaso" (2008, p. 162). De esta manera se puede concluir que los zapatistas emplean la palabra para definir su identidad de lucha; la metáfora para denunciar el mal del sistema capitalista; y el discurso para quebrar la coherencia de la guerra que el sistema viene ofreciendo como paz.

TRUMP Y LA NAVAJA DE OCKHAM

La primera parte del comunicado es la más teórica y en ella se emplea un género discursivo donde se enumeran una serie de actos que pretenden ser denunciados. Las primeras líneas sirven 
para encuadrar el comunicado situándole en relación con el primer intertexto que aparece: la correspondencia que mantuvo el Subcomandante Insurgente Marcos con Don Luis Villoro Toranzo en el año del 2010 y que fue hecha pública a inicios del 2011.

Siguiendo a Laclau, las prácticas que articulan el fenómeno político generan una identidad colectiva y, en este caso, el discurso zapatista sirve para exponer el carácter antagonista de acontecimientos históricos. En Emancipación y diferencia defiende Laclau la idea de que una política democrática es la que "acepta plenamente la naturaleza plural y fragmentada de las sociedades contemporáneas" (1996: 119) y a la vez que la creación de una identidad alternativa de resistencia sólo puede construirse aceptando el sistema de poder del que brota ya que aunque éste le impide ser, es a la vez el que condiciona su existencia. En el caso que nos ocupa, el SIG no puede crear un discurso otro sin asumir por completo el discurso hegemónico: lo que se dice en la prensa, en la televisión, este lo conoce, lo entiende y desde ese conocimiento lo ataca.

Este texto se publica meses antes del inicio de la campaña presidencial del pasado julio del 2018 y en él se aprecia una intención de repasar la política actual mexicana. Aunque después retiró su candidatura, Margarita Zavala tenía intención de presentarse a las elecciones del 2018. En este comunicado se la nombra como "la señora Margarita Ester Zavala Gómez del Campo de Calderón” (SupGaleano, 2017c) con un tono irónico ya que el SIG quiere mostrar que es mucho más respetuoso que los otros zapatistas, que, como dice el comunicado, le llaman irrespetuosamente "la Calderona". A continuación se van desmenuzando los apellidos de la candidata para demostrar que son apellidos vinculados a la dejadez y a la complicidad con la violencia sufrida en México. El discurso tiene el objetivo de denunciar a la candidata Zavala, a la Iglesia, al gobierno mexicano y a Trump por ofrecer explicaciones de la realidad muy poco basadas en hechos factuales y, a este último, además, por ser responsable de un crimen contra la humanidad entera. Por una parte, se describe cómo el también candidato a la presidencia del 2018, José Antonio Meade Kuribreña, el teólogo mexicano Alberto Villasana y el cardenal Juan Sandoval Iñiguez explican el terremoto del 19 de septiembre de 2017 como un castigo divino enviado a México por, entre otras cosas aprobar la ley del aborto. Por otra parte, el Papa Francisco explica las causas del terremoto argumentando que "México es privilegiado en el martirio por haber reconocido, defendido a su madre" (ibid.) y por eso es el demonio el que castiga al país. Ante estos comentarios hechos por "expertos" que han protagonizado los medios de comunicación, el SIG divide a la sociedad en dos claros bandos cuando asegura que: "hay quien pide perdón divino o abraza el dolor como martirio privilegiado... y hay quien se organiza para demandar verdad y justicia” (ibíd.). Es decir que en un bando están los dos bandos del discurso hegemónico, la derecha y la izquierda, el PRI y el PAN, en el otro están los que abrazan el Tercer Espacio, que es el único espacio que apuesta por la vida en su conjunto.

El gobierno mexicano es criticado en primera instancia a través de una mención al presidente "aficionado a los videojuegos bélicos, Felipe Calderón Hinojosa" (ibíd.), acusado de utilizar la guerra contra el narcotráfico para conseguir una militarización en varias regiones de México. El SIG hace en esta crítica una clara alusión a la Ley de Seguridad Interior aprobada el 30 de noviembre de 2017 (Animal Político 2017) que criminaliza la protesta social y crea inseguridad y muerte entre los pueblos indígenas. 
Seguidamente se critica al Gobierno por no haberse hecho cargo de responsabilidades relacionadas con el incendio en la guardería ABC, ocurrido el 5 de junio del 2009, donde murieron casi 50 niños, las inundaciones del estado de Tabasco durante la presidencia de Felipe Calderón Hinojosa y las tragedias de Acteal, Ayotzinapa y Atenco. Ricardo Anaya, del partido de la oposición PAN recibe así mismo una crítica que lo sitúa en el mismo nivel que los anteriores a través de los siguientes términos "corrupción, el cinismo, la traición, el fanatismo, la intolerancia, la soberbia, el nepotismo, la ignorancia, el cretinismo...” (Ibídem).

La pretensión de estas líneas es interpretada, a través del concepto de Bhabha, como un deseo de crear un Tercer Espacio, que quiebre la bipolaridad de la política hegemónica y sea protagonizado por un nuevo "nosotros" que incluye a "los otros" (Bhabha, 1994: 205). Este Tercer Espacio puede entenderse también aplicando ciertas nociones de Laclau sobre el "significante vacío": los zapatistas han modificado las demandas de su lucha con el transcurrir de estos 25 años. Además han ido asumiendo múltiples luchas que estaban dispersas en la sociedad civil y en los diferentes movimientos antisistema. En el momento actual se está dando, a mi entender, un momento de ruptura en el que la multiplicidad de luchas separadas se está aunando en torno al respeto a la mujer y al planeta Tierra. Para Laclau, el primer significado de una reivindicación sirve para hacerla diferente de otras, mientras que el segundo significado sirve para hacerla igual a la demás, de tal suerte que si la función de los significantes vacíos es renunciar a su identidad de lucha diferente con el fin de representar la identidad equivalencial de un espacio comunitario global estos significantes vacíos no pueden construir la identidad equivalencial como algo diferente (Laclau, 1996: 78 y ss.) sino como algo equivalencial. Así el zapatismo está reconstruyendo su identidad a través de la asunción del significante vacío "mujer" que representa hoy a la humanidad entera.

Esta hipótesis queda parcialmente confirmada por ejemplo cuando en el comunicado, el gobierno de Estados Unidos, representado por "Ronaldo Trump" es acusado de genocida ya que a través de numerosas declaraciones públicas en twitter, etc en contra de la mujer ha dejado claro que "la víctima es el planeta entero, incluida la humanidad que lo habita" (SupGaleano, 2017c).

Y aquí es donde aparece la referencia a la navaja de Ockham que le sirve a SIG para explicar cómo Trump ha interpretado el silogismo de Ockham: la solución más sencilla para permanecer en el poder es una guerra.

A continuación se compara a Trump con el emperador romano Nerón, famoso por su instinto destructivo. El discurso se vuelve radical cuando anuncia un crimen sin precedentes y apocalíptico: "como si el mundo tal y como lo conocemos se derrumbara" (ibíd.).

\section{EL GATO DE SCHRÖDINGER}

En la segunda parte del comunicado se nos ofrece un juego: el texto está originariamente dirigido a un auditorio, por tanto, el receptor del mensaje es apelado a través del uso de vocativos. Este receptor va cambiando paulatinamente desde la primera persona del plural "imaginemos que tenemos un sueño" (SupGaleano, 2017c), al poco el receptor es la segunda persona del plural "supongan ustedes" (ibid.) y unas líneas más adelante se transforma en la segunda persona del singular "usted puede pensar, con un alto grado de certeza, que está en el mundo real" (ibíd.). 
En esta parte del comunicado el SIG parodia el discurso dominante y a la vez parodia su propia aparente ignorancia ante términos usuales en ese discurso dominante que, en este caso concreto, es el del léxico de los video-juegos. Así señala:

Algo así como una combinación de la estrategia en tiempo real, el role playing, la primera persona o first person shooter, y el otro que no sé cómo se llama pero es como en tercera persona (ibid.).

La superficie interna de la esfera, la que ustedes pueden ver, es una gran pantalla curva, con tecnología $5 \mathrm{~K}$, omled o como se diga (ibid.).

En ambos casos, las citas tienen numerosas expresiones anglosajonas intraducibles al castellano, lo que pone de manifiesto cómo el lenguaje inventa la realidad y cómo este genera una relación de poder sobre los que lo hablan a diferencia de los que no lo hablan y solo lo balbucean, como el SIG. De esta manera se pone de manifiesto que los que ostentan el poder lingüístico inventan la realidad.

A continuación se invita al receptor a imaginarse metido en una esfera ideal controlada por la realidad virtual pero en la que uno se siente, paradójicamente, en la realidad real. Esta esfera es una metáfora de la aceptación de la lógica de "los de arriba" que el texto pretende mostrar como irreal, falsa y artificial, es decir que compara a la realidad de los de arriba con un video-juego y a todos nosotros con jugadores que confunden el juego con la realidad. Se me antoja vincular esta metáfora con un juego de espejos cervantino donde se confunde realidad y ficción y el que cree estar cuerdo está loco y el loco, el que confunde molinos con gigantes, es el único cuerdo. Esta es, a mi entender, la principal ruptura binomial del comunicado, la que separa la realidad de la ficción a través de una ficción que no hace sino parodiar la realidad de los que asumen que las reglas del juego son las mismas que las reglas de la realidad. Me explico; este texto tiene la intención de hacer ver que estamos dentro de un juego controlado, el de la Modernidad, del que no podemos escapar: todos somos el gato de Schrödinger y, según este experimento de mecánica cuántica, se puede estar muerto y vivo a la vez. En esta supuesta esfera (o caja opaca y cerrada), en esta ficción, surge de repente, como un fallo del sistema, la figura de un personaje inesperado: "Usted, claro está, es una persona moderna, comprensiva de las limitaciones tecnológicas y atribuye esa irrupción a una irregularidad en el complicado software de la máquina o en su complejo hardware" (ibid.).

Esa figura se crea como un personaje supuesto ya que el narrador insiste una y otra vez en que todo lo que esta contando "sólo" se supone. Sin embargo, los rasgos de este personaje nos evocan irrevocablemente a la que iba a ser candidata a las elecciones por parte del Consejo Nacional Indígena, Marichuy. La máquina la define bajo los siguientes patrones: "mujer", "estatura promedio", "indígena”, y continúa: 
nulo o mínimo nivel de estudios escolares, acceso a avances tecnológicos entre 0 y 0,1 , monolingüe aunque hay casos en que maneja dos o más idiomas, tasa de mortalidad, muy por encima del promedio, esperanza de vida, muy por debajo del promedio; persistencia cultural, siglos; por lo mismo, edad indefinida (ibid.).

Esta "literaturización" de un personaje real es una inversión del papel fundamental de la literatura en la que normalmente se presenta la no-realidad como si esta sí existiera, al mismo tiempo que rompe con la convención del discurso político (Vanden Berghe, 2007). La parodia, el enfrentamiento entre lo "moderno" y lo "premoderno" y sobre todo el uso constante de auto ironía son aquí lo que conforman el Tercer Espacio, como espacio abierto que incluye la voz del otro situada en paralelo a la voz del yo, entendido si se quiere a través de la exotopía, ese "encontrarse fuera" que implica la transformación de "uno-mismo" en "otro-mismo".

\section{EL GATO-PERRO}

El gato-perro es la figura intertextual más representativa de este comunicado ya que se conoce desde antes que me muriera el Subcomandante Marcos. Marcos es quien la presenta en otro comunicado llamado "Rebobinar 3" del 17 de noviembre 2013 donde se cuenta el encuentro entre este y el escarabajo Don Durito de la Lacandona:

El gato-perro es una incógnita para biólogos terrestres y marinos (¿en qué tabla de clasificación de los seres vivos acomodamos este caso?), caso irresoluble para la psicología (una cirugía neuronal no descubre el centro cerebral que define la perrunez o la gatez), misterio para la antropología (¿los usos y costumbres al mismo tiempo semejantes y antitéticos?), desesperación para la jurisprudencia (¿qué derechos y deberes emanan del ser y no ser?), el santo grial de la ingeniería genética (imposible privatizar ese escurridizo ADN). En suma: el eslabón perdido que echaría abajo todo el darwinismo de laboratorio, cátedra, simposio, reiterada moda científica (S.I.M., 2013).

Gato-perro es además el nombre que se le da en el comunicado que aquí se analiza a la máquina esférica desde donde se narra la segunda mitad del mismo. El SIG inventa el nombre de esta máquina e irónicamente se hace con sus derechos de autor, convirtiendo en parodia la economía capitalista donde todo se compra y vende: "la máquina del gato-perro, (todos los derechos reservados)" (SupGaleano, 2017c).

Poco más tarde el gato-perro es, según la interpretación de la máquina, un "ser mitológico de origen desconocido; no hay ningún dato que confirme su existencia real, o sea virtual, pero real en la máquina, o sea, usted me entiende ¿no?, bueno, depende; hábitat probable: montañas del sureste mexicano" (ibíd.).

El gato-perro es, a mi entender, el emblema por antonomasia del Tercer Espacio, que no es tercero sino híbrido, múltiple, contradictorio y mutante. Esta figura representa lo diferente, lo nuevo, que mezcla pasado y futuro y que es, en realidad, metáfora del presente. A este respecto el SIG dirá que mientras los cuentos tradicionales comienzan con un "había una vez" y los cuentos zapatistas con "habrá una vez", los cuentos del gato-perro se inician con un "hay esta vez" ya que transcurren en el tiempo real (SupGaleano, 2015). Este tiempo real del gato-perro es, por estar en el presente, impredecible y cambiable. Recuerda a lo que contestó Marcos en el 1996 cuando le preguntaron qué esperaba del ya histórico Primer Encuentro Intercontinental por la Humanidad 
y contra el Neoliberalismo y contestó que no tenía la menor idea, ante lo que Regís Debray comentó "This is a return to the essential resistance" (Proyect, 2003). El gato-perro nos devuelve el hálito de la resistencia substancial.

DEL CUADERNO DE APUNTES DEL GATO-PERRO: EL MISTERIOSO CASO DE LAS MANTECADAS DESAPARECIDAS

Bajo este título que podría considerarse un paratexto del texto principal se encuentra la parte más literaria de todas. Al estar incluido en la ponencia en un seminario titulado "ConCiencias por la Humanidad: las Ciencias frente al muro", resulta una estrategia peculiar que mezcla interdiscursividad e intertextualidad. Excluyendo al gato-perro el resto de los personajes aparecidos hasta ahora son todos personas reales. En este apartado el SIG presenta a Elías Contreras, personaje de ficción cuyo origen se remonta a la novela negra escrita a cuatro manos por Paco Ignacio Taibo II y el Subcomandante Marcos en el 2005 bajo el título de Muertos incómodos (falta lo que falta). Elías Contreras está muerto y representa la voz de todos los zapatistas muertos en 1994. Elías Contreras salta muy a menudo de la novela a los muchos y diversos textos escritos tanto por Marcos como por el SIG. Este personaje otorga a la ponencia un elemento de ruptura con la práctica tradicional de la construcción de un discurso de resistencia social, pero en la práctica zapatista de combinar registros, géneros y voces este tipo de ruptura es absolutamente habitual, tanto que el propio Marcos lo llama "los "modos" del hablar zapatista" (S.I.M., 2007).

Como detective de la Comisión de Investigación que es, Elías es llamado a investigar la desaparición de unas mantecadas de la tienda cooperativa de la región. Este hecho aparentemente banal sirve de contraste con la función de Elías en el imaginario zapatista, descrita en la novela Muertos incómodos (Taibo II, 2005). En esta novela Elías Contreras debía enfrentarse al Mal y al Malo. La búsqueda de unas mantecadas parece, pues, una tarea menor. En realidad sirve como contraste al resto del comunicado donde se habla de un crimen contra toda la humanidad, y de las otras dos participaciones, una anterior y otra posterior, en las que se habla de "miles de crímenes con minúsculas, que se alimentan de un crimen mayor"(SupGaleano, 2017a) y de que "si no lo detenemos al criminal, pues ahora sí que todo el mundo es la víctima, que sea no sólo la gente, también todo, los animales, las plantitas, las piedras, el agua, todo pues" (SupGaleano, 2017b), respectivamente. En este relato han desaparecido unas mantecadas y el misterioso caso ha de ser resuelto para hacer justicia y para condenar al culpable. El SIG está narrando la historia y a la vez está dentro de la historia, es decir es a la vez narrador y personaje. Las mantecadas han sido comidas por otro personaje de ficción nacido de la pluma del SIG, la niña llamada Defensa zapatista y su mascota, el gato-perro. El hecho de que se alimenten de mantecadas es, como expone en la ponencia de clausura el SIG, lo que hace a Defensa zapatista "una niña normal y no un organismo cibernético, creado por la mente perversa del SupMarcos para molestarnos [...] cuya fuente de energía no es la solar ni la atómica, sino las mantecadas (ibíd.).

En el relato se ven numerosos ejemplos de heterofonía ya que se combina la lengua del narrador con la lengua popular de Elías. Este personaje, mejor escuchador que hablador, en este cuento habla muy poco, pero su presencia nos ayuda a imaginar la cotidianidad de las comunidades zapatistas que solucionan sus problemas a su modo práctico y diferente a la lógica 
del modo capitalista: el castigo por robar es hacer las cuentas de las cooperativas y así devolver las mantecadas al colectivo a través de un trabajo que favorezca a toda la comunidad.

Lo más destacado es que el SIG cumple su castigo sin queja y su ejecución le sirve para denunciar una de las injusticias a las que el EZLN y el CNI se han visto expuestos durante la campaña electoral de Marichuy. Las cuentas las realiza con un celular que "sí jalaba para sumas y restas" (ibid.) pero no sirve "para capturar las firmas que el INE del primer mundo ponía como requisitos a aspirantes a candidatas del tercer mundo" (ibíd.).

\section{LA MUJER, SÍMBOLO DE LA LUCHA ZAPATISTA HOY}

Este comunicado ha de ser leído a la luz de los comunicados anterior y posterior para poder concluir que la mujer se convierte en símbolo de la lucha zapatista debido a una violencia de género sin igual. En el comunicado del 27 de diciembre, titulado "Depende" hay un párrafo entero de preguntas retóricas que manifiestan el miedo cotidiano de la mujer a ser asesinada y a que su muerte quede impune y que termina describiendo todo tipo de mujer:

¿Mi asesino, sí, en masculino, será castigado?, ¿Quién explicará qué del crimen que me atacó por ser mujer? Sí, joven, niña, adulta, madura, anciana, bonita, fea, flaca, gorda, alta, baja, siempre mujer (SupGaleano, 2017a).

Un poco más adelante se compara a los indígenas con las mujeres para crear un paralelismo que confirma la transformación de la mujer en la víctima por la que el movimiento zapatista ha de luchar:

Decía el finado SupMarcos que, para ser tomados en cuenta, los indígenas tenían que morirse por miles. Que si eran unos cuantos, normal. Que si eran unas decenas, "es parte de su naturaleza bárbara”, (...). Que si eran cientos, “jah, las desgracias naturales, pobrecillos!”. Si ya eran miles, entonces sí alguien preguntaba “¿qué está pasando?, ¿por qué?”. Así que cabría preguntarse: ¿Cuántas mujeres asesinadas se necesitan para que nos preguntemos qué está pasando y por qué? (ibíd.).

El SIG continúa desarrollando ejemplos y argumentos que le hacen concluir que el crimen contra los indígenas y contra las mujeres en realidad es consecuencia del sistema neoliberal iniciado con la Modernidad, más bien que el sistema neoliberal es el crimen en sí.

Las mujeres son víctimas y a la vez protagonistas de la lucha por la vida y son el ejemplo de otredad emblemático en el sistema patriarcal. El discurso zapatista actual exige acudir a la mujer para trasformar su otredad en un ejercicio de exotopía: "no me tengas lástima, no te pido limosna, sólo te digo: mírate al mirarme, y al escucharme, escúchate” (ibid.).

El comunicado del 30 de diciembre titulado "Del cuaderno de apuntes del gato-perro" es un ejemplo de intertextualidad en el que los famosos personajes de Sir Arthur Conan Doyle, Sherlock Holmes y Doctor Watson llegan a tierras zapatistas y entran en contacto con otro detective de ficción salido de la pluma de Marcos, el susodicho Elías Contreras. Estos personajes han de resolver el mismo crimen del que se viene hablando en los dos comunicados anteriores. Así explica Contreras el caso a su colega Holmes: 
O sea que lo sabemos quién es el asesino, quién es la víctima, cuál es el arma que se usó, y cuál es como quien dice la escena del crimen o sea dónde mero se hizo la chingadera, y su tiempo (SupGaleano, 2017b).

Lo más destacado de este último comunicado es la última parte cuando se describe el momento en el que Defensa Zapatista decide hablar únicamente a través de colores:

Hubo unos días, no hará muchas lunas, que la niña Defensa Zapatista decidió expresarse verbalmente únicamente con colores. Y no con expresiones del tipo "esto es azul" o "sentí naranja" o cosas así, sino únicamente nombres de colores. Todas las teorías del lenguaje y del discurso, fueron puestas en jaque por la impertinencia de una niña indígena y zapatista (ibid.).

Este es el caso más radical de exotopía en el que la compresión de la niña zapatista implica un esfuerzo de empatía que obliga a ser uno mismo a través del otro. Este comunicado confirma que Defensa Zapatista viene a representar la ideología zapatista actual. Así como el más alto cargo de un zapatista es el de ser Subcomandante, la niña zapatista elige ser "defensa" en la lucha por un mundo mejor, la cual ha de realizarse en colectivo, en equipo. A la vez el intento de hablar a través de colores implica que el lenguaje construye la realidad y que la realidad del mundo mejor anhelado por los zapatistas no tiene aún un lenguaje ya que solo es posibilidad y para expresarlo son necesarias "nuevas formas de comunicación" (ibid.). Como el propio SIG escribe a continuación "No me imagino algo más zapatista que lo que en el esfuerzo de esa niña se sintetiza" (Ibid.).

De esta manera el SIG narra la misma historia a través de las ponencias de tres días diferentes, lo que da una sensación de relato inacabado. Este "modo" de crear un discurso político es la expresión de la apertura a lo incompleto del movimiento zapatista, que bien podría resumirse con la frase, tan zapatista, de "falta lo que falta".

\section{CONCLUSIONES}

Con estas líneas se quiere concluir que la hipótesis de este trabajo basada en que el movimiento zapatista está constituyendo una nueva identidad se refleja en diferentes puntos del comunicado que he analizado. En el presente artículo se puede observar cómo el movimiento zapatista desde que el SubMarcos ha sido remplazado por el Subcomandante Galeano, es decir, desde 2014, ha radicalizado su denuncia del régimen capitalista opresor. Esta radicalización tiene como objetivo el globalizar la lucha antisistema zapatista más allá de la lucha por justicia entre los indígenas del sur de México. El discurso zapatista propone un nuevo actor social: la humanidad. Con este nuevo actor social se pretende rebasar las fronteras geográficas y los desacuerdos políticos: la lucha zapatista es ahora a vida o muerte.

Desde el uno de enero de 1994 el EZLN ha contado con ciertos ejes identitarios capaces de tener la fuerza necesaria como para captar la atención nacional e internacional de otros grupos que se han sentido identificados con el movimiento zapatista: feministas, pacifistas, ecologistas, altermundistas, colectivos gays, estudiantes, anarquistas, intelectuales, etc. (Leyva, 1999). Esta red creciente de actores provenientes de la sociedad civil global ha venido siendo un gran desafío a la hora de conciliar las demandas concretas de un grupo secularmente oprimido en un lugar 
concreto del planeta y las demandas heterogéneas de diversos grupos minoritarios u oprimidos. El concepto del Tercer Espacio me ha servido para explicar que el discurso zapatista es una construcción simbólica capaz de aglutinar diferentes demandas a través del uso de una serie de elementos discursivos híbridos de difícil calificación.

La ponencia "Trump, la navaja de Ockham, el gato de Schrodinger y el gato-perro" continúa la trayectoria del Subcomandante Marcos, pero es un claro ejemplo de la nueva estrategia discursiva utilizada por el SIG, cuyos comunicados están empeñados en "equivalenciar" las demandas "diferenciales", es decir en globalizar el objetivo de las múltiples luchas sociales del planeta, cuyo significante último es el planeta Tierra, simbolizado por la mujer, como significante abstracto.

Este cambio en el discurso político viene de la mano de uno de los mayores cambios estratégicos ocurridos en el seno del EZLN: la decisión de presentar una candidatura a las elecciones presidenciales del 2018. Como señala Luis Hernández Navarro, la campaña de Marichuy además de demostrar que "la verdadera transición democrática sigue siendo asunto pendiente central de la agenda política nacional"(Hernández Navarro, 2018) ha despertado lo que el SIG bautizó como "el efecto Marichuy", una revitalización de aquel lejano "efecto Chiapas" que ahora quiere ser un proyecto revolucionario universal.

La radicalización se ve claramente en la ruptura constante de los binomios nosotros/ellos o realidad/ficción, sobre todo en la parte de la máquina "gato-perro", con la intención de aunar a la humanidad en una misma lucha, la de la supervivencia. El SIG desautoriza por completo al gobierno mexicano, a la Iglesia, incluido el Papa y al presidente de la nación vecina Trump, representante del Mal que Elías Contreras se empeña en encontrar y le otorga a Marichuy, símbolo de la triple condena del ser por su condición de mujer, indígena y rebelde, la autoridad de poder salvar a la humanidad y a Defensa Zapatista, el papel de mantener la utopía zapatista basada en la posibilidad de un mundo mejor.

Retomando las preguntas de la introducción se puede concluir que la mujer es el actorvíctima protagonista de la lucha zapatista enfrentada al anti protagonista de siempre, el capitalismo, que no sólo es interpretado desde su ángulo económico si no sobre todo desde la construcción patriarcal que le sostiene y que además es considerado como un sistema-crimen (SupGaleano, 2017a). Además de ser víctima la mujer, Marichuy o Defensa Zapatista, es el exponente de la lucha, responsable de llevarla a cabo a través de su responsabilidad con la humanidad entera.

La estrategia política que el EZLN, aunado bajo el marco del CNI, llevó a cabo en los últimos meses durante la campaña pre-electoral de Marichuy fue la de arriesgar su identidad colectiva para construir una nueva. El hecho de que los zapatistas se hayan venido negando a tomar el poder durante casi 25 años ha hecho que Marichuy suponga una sorpresa estratégica. A mi entender el fracaso de la campaña, la imposibilidad de conseguir las firmas necesarias y los accidentes sufridos durante esta campaña han puesto de manifiesto que los zapatistas son aún un movimiento que denuncia la injusticia, cuestiona la democracia representativa y de líder y se empeña en representar a los que están abajo y a la izquierda, en contra del sistema patriarcal y económico del neoliberalismo. 
El discurso zapatista hoy supera la relación antagónica entre dos partidos políticos obsoletos y la inmutabilidad de la izquierda mexicana por seguir una y otra vez el mismo patrón desgastado. La importancia del mismo se debe paradójicamente más a sus fracasos que a sus éxitos. Gracias a Marichuy, los indígenas, a pesar de no participar en las elecciones, se han forjado el compromiso de transformar el mundo manteniendo el equilibrio entre la renovación de su estrategia política a nivel nacional y la responsabilidad de cuidar las estructuras comunitarias basadas en el bien colectivo. Gracias a Defensa Zapatista el discurso zapatista se renueva en su enfrentamiento al lenguaje establecido y en busca de una palabra nueva, un significante nuevo que pueda explicar el significado de la esperanza zapatista. Hoy en día el discurso zapatista ha transformado a la mujer indígena en emblema de un sujeto social global y su propuesta política nacional representada en la figura de Marichuy se ha visto más que nunca apoyada en la invención de formas renovadas de encuentros comunitarios con la participación de actores diversos de la sociedad civil mexicana e internacional. A la pregunta de cuál es su proyecto de nación, siguen, dignos, contestando: "otro mundo es posible" (Espoir Chiapas, 2017). 
BIBLIOGRAFÍA

ANIMAL POLÍtico (2017). "8 puntos clave de la Ley de Seguridad Interior aprobada por los diputados".

ANSOTEGUi, Elena.“Todos somos Marichuy: género, poder y utopía en los zapatistas hoy”. Sociedad y Discurso, 32 (2018): 84-102.

BAjtin, Mijaíl (1997). Hacia una filosofía del acto ético. De los borradores y otros escritos. Barcelona: Anthropos.

BAKHTIN, Mikhail (1981). The Dialogical Imagination: Four Essays. Austin: University of Texas Press.

BBC Mundo. "México: el brutal caso de las 11 mujeres de Atenco que complica a Peña Nieto". BBC Mundo (2016).

BHABHA, Homi (1994). "Cultural Diversity and Cultural Differences". Ashcroft, B. (ed.). PostColonial Studies Reader. London: Routledge: 206-209.

BHABHA, Homi (2002). El lugar de la cultura. Buenos Aires: Manantial.

CECEÑA, Ana Esther (2001). "El zapatismo como subversor de la teoría y práctica revolucionarias”. Actuel Marx: ¿Pensamiento único en filosofía política?, 1 (2001): Argentina: Kohen: 159-167.

CHIAPAS, Espoir (2017). "Marichuy: El proyecto que dirige México es el capitalismo y está atentando contra los habitantes".

DUBET, François. "De la sociología de la acción a la sociología del sujeto". Estudios Sociológicos, 7 (1989): 519-536.

GARCÍA Agustín, Óscar. "Ni el centro ni la periferia: La construcción del Tercer Espacio en los textos del Subcomandante Marcos". Discurso y Sociedad, 3(2) (2009): 280-315.

García de LeÓn, A.; Monsiváis, C.; Rodríguez, H. (2001). EZLN Documentos y Comunicados 2. 15 de agosto de 1994 a 29 de septiembre de 1995. México: Ediciones ERA.

GÓMEZ, Magdalena. “Marichuy en la UNAM: apoyar y repensar”. La Jornada (2017).

HERNÁNDEZ NAVARRO, Luis. “Marichuy y la exclusión política”. La Jornada (2018).

Inter Press Service. "México: Regis Debray elogia "realismo" del EZLN”. IPS (1996).

LACLAU, Ernesto (1996). Emancipación y diferencia. Buenos Aires: Ariel.

LE Bot, Yvonne y Subcomandante Marcos (1997). El sueño zapatista. Barcelona: Anagrama.

LEYvA, Xochitl (1999). "De las Cañadas a Europa: niveles, actores y discursos del nuevo movimiento zapatista (1994-1997)". Desacatos, 1: 56-77.

Melucci, Alberto (1999). Acción colectiva, vida cotidiana y democracia. México: Colegio de México.

Proyect, Louis (2003). "Fetishizing the Zapatistas: a critique of "Change the World Without Taking Power"”." Columbia University. 
SILVESTRI, Adriana et al. (1993). Bajtín y Vigotsky: la organización semiótica de la conciencia. Barcelona: Anthropos.

S.I.M. "Introducción o presentación (o las dos cosas) al libro EZLN: 20 y 10, el fuego y la palabra”. Enlace Zapatista (2003).

S.I.M. “Mujeres sin miedo, todas somos Atenco”. Enlace Zapatista (2006).

S.I.M. “Coloquio Aubry. Parte II. Escuchar el Amarillo”. Enlace Zapatista (2007a).

S.I.M. “Coloquio Aubry. Parte VII (y última). Sentir el Rojo”. Enlace Zapatista (2007b).

S.I.M. "Rebobinar 3”. Enlace Zapatista (2013).

S.I.M. "Entre la luz y la sombra". Youtube (2014).

S. I. Moisés y S. I. Galeano (2017a). "La primera de varias”. Enlace Zapatista (2017a).

S. I. Moisés y S. I. Galeano. "Los muros arriba. Las grietas abajo (y a la izquierda)". Enlace Zapatista (2017b).

SupGaleano. "Del Gato-Perro: El navío y la Otroas". Seminario "El Pensamiento crítico frente a la Hidra Capitalista", realizado en el CIDECI-Unitierra del 3 al 9 de mayo de 2015. Youtube.

SupGaleano. "Depende". Participación de la Comisión Sexta del día 27 de diciembre de 2017 en el ConCiencias por la Humanidad. Enlace Zapatista (2017a).

SupGaleano. "Del cuaderno de apuntes del gato-perro". Participación de la Comisión Sexta del EZLN en la clausura del ConCiencias por la Humanidad. Enlace Zapatista (2017b).

SuPGALEANO. "Trump, la navaja de Ockham, el gato de Schrodinger y el gato-perro". Enlace Zapatista (2017c).

SupGaLEANO (2017d). "Trump, la navaja de Ockham, el gato de Schrodinger y el gatoperro" (audio). Radio Zapatista (2017d).

SupGaleANO (2017e). "Trump, la navaja de Ockham, el gato de Schrodinger y el gatoperro" (English). Radio Zapatista (2017e).

TAIBO II, Paco Ignacio y Subcomandante Marcos (2005). Muertos incómodos (falta lo que falta). México: Planeta.

TODOROV, Tzvetan (1987). La conquista de América, el problema del otro. Madrid: Siglo XXI.

TODOROv, Tzvetan (2008). El miedo a los bárbaros. Barcelona: Galaxia Gutenberg/ Círculo de Lectores.

VANDEN BERGHE, Kristine. "Sobre armas y letras. El Quijote como intertexto en los relatos del Subcomandante Marcos”. Boletín AFEHC, 33 (2007).

ZAID, Gabriel. (2011). De los libros al poder. Madrid: Debolsillo.

ZaVALA, Iris (1997). "Bajtin y el acto ético: una lectura al reverso". Hacia una filosofía del acto ético. De los borradores y otros escritos. Barcelona: Anthropos. 
ZBINDEN, Karine. "El yo, el otro y el tercero: el legado de Bajtín en Todorov". Acta poética, 27(1) (2006): 325-339.

ZERMEÑO, Sergio (2005). La desmodernidad mexicana y las alternativas a la violencia y a la exclusión en nuestros días. México: Océano. 